RESEARCH ARTICLE

\title{
Phenotypic Diversity and Molecular diversity of Finger Millet Composite Collection and Identification of Trait Specific Germplasm for Use in Crop Improvement
}

\author{
A.Bharathi* \\ * Assistant Professor, Department of Crop Improvement, Agricultural College and Research Institute, Eachangkottai, Thanjavur
}

\begin{abstract}
A composite collection of finger millet consisting of 1000 accessions representing the diversity of the entire germplasm at ICRISAT gene bank was developed, including 622 accessions of ICRISAT core collection. Phenotyping of the composite collection for 15 quantitative traits and 20 SSR markers genotyping data resulted in the identification of promising traitspecific accessions. Principal component analysis with seven components indicated relative importance of the traits (days to $50 \%$ flowering, plant height, peduncle length, ear head length, and panicle exertion) to total divergence. Clustering analysis grouped biological races into three clusters wherein cultivated races vulgaris, plana, elongata, and compacta were grouped in Cluster I and wild races spontanea in Cluster II and africana in Cluster III. Accessions were identified as useful for important traits such as early flowering (34), high grain yield (38), fodder yield (19); more fingers (29); basal tiller number (25) and ear head length (28). 0
\end{abstract}

Received : $27^{\text {th }}$ October, 2020

Revised : $10^{\text {th }}$ November, 2020

Revised : $21^{\text {st }}$ November, 2020

Accepted : $28^{\text {th }}$ November, 2020

Keywords: Phenotypic diversity; Finger millet; Trait specific germplasm; Principal component analysis; Cluster analysis.

\section{INTRODUCTION}

Finger millet (Eleusine coracana L. Gaertn) is an important crop in several countries of Asia and Africa used for food, fodder, and industrial purpose. Precise data of area and production under finger millet is not known because the production statistics of this crop has often been clubbed with other millets. At present 55 to 60 per cent of the finger millet crop is grown in Southern and Central Africa, and most of the remaining areproduced in India and Nepal. The Consultative Group on International Agricultural Research (CGIAR) has estimated that $10 \%$ of the area under millets is with finger millet. , The global area under finger millet, is 3.38 million hectares with aproduction of 3.76 million tonnes. Finger millet was domesticated about 5000 years ago in Eastern Africa (possibly Ethiopia) and introduced into India 3000 years ago. The closest wild relative of finger millet is $E$. coracana subsp. africana, which is a native of Africa.

Finger millet can perform better under adverse soil and weather conditions compared to other crops. The finger millet germplasm consisting of5949 accessions was conserved in International Crops Research Institute for the Semi-Arid Tropics (ICRISAT) gene bank. A composite collection that constituted 1000 accessions was developed (Upadhyaya et al., *Corresponding author's e-mail: bharat22880@yahoo.co.uk 2006b) under the Generation Challenge Program to unlock genetic diversity. The aim of the present investigation was to evaluate global composite collection for various morpho -agronomic traits at multi-locations and to identify trait-specific diverse accessions for use in breeding programme.

\section{MATERIAL AND METHODS}

The composite collection of 1000 accessions along with the four control cultivars, VR708, VL149, PR202 and RAU8 were evaluated in an augmented design in three environments (2005-2006 post rainy (E1) at Coimbatore, 2006 rainy (E2) and 2007 rainy (E3) seasons at ICRISAT Centre, Patancheru, India. The Total 111 blocks were maintained with 9 test entries and one check variety. The length of each row is $6 \mathrm{~m}$, the spacing between plants were maintained $30 \times 15 \mathrm{~cm}$. Data was recorded on 15 quantitative traits such as days to $50 \%$ flowering, plant height, basal tillers, culm branching, flag leaf blade length and width, flag leaf sheath length, peduncle length, panicle exsertion, inflorescence length and width, length and width of longest finger, and grain yield. The random model of residual maximum likelihood (REML) in GenStat 10 (Payne et al., 2007) was used to analyze data of 15 quantitative traits for the individual location. Variance components owing to genotype $\left(\sigma^{2} g\right)$ and its standard errors (SE) were $107 \mid$ | 10-12 | 408 
estimated for individual and combined analysis. Best Linear Unbiased Predictors (BLUPS) for individual location and combined analysis were worked out for all quantitative traits. Correlations were calculated on BULP for all the traits. The Shannon- Weaver diversity index $\left(\mathrm{H}^{`}\right)$ (Shannon and Weaver, 1949) was calculated for the entire set, different races for quantitative traits. Principal Component Analysis (PCA) on Genstat 10 (Payne et al., 2007) was used to know the importance of different traits in explaining multivariate polymorphism. Cluster analysis was performed based on biological races using the scores of first four PCs following Ward (1963). These 1000 accessions of finger millet composite collection weregenotyped with 20 polymorphic SSR markers. Based on the dissimilarity index, the most diverse pair of accessions were identified.

\section{RESULTS AND DISCUSSION}

\section{Variances}

The variances of the cultivated and wild races were homogenous for most of the trait except days to $50 \%$ flowering and ear head width in E1, days to $50 \%$ flowering, ear head length and length of longest finger in E2, flag leaf blade length, ear head length, the width of longest finger, and the number of fingers in E3, days to 50\% flowering, width of longest finger, ear head length, ear head width in combined (data not given).

Table 1. Correlation coefficients more than 0.500 or less $\mathbf{- 0 . 5 0 0}$ among different traits in finger millet composite collection

\begin{tabular}{|c|c|c|c|c|c|}
\hline Traits & Plant height & Panicle excertion & $\begin{array}{l}\text { Length of longest } \\
\text { finger }\end{array}$ & $\begin{array}{c}\text { Width of } \\
\text { longest finger }\end{array}$ & Finger number \\
\hline Days to $50 \%$ flowering & 0.981 (E1) 0.542 (E3) & & & & \\
\hline Basal tiller number & $0.770(\mathrm{E} 1)$ & & & & \\
\hline Flag leaf blade length & 0.844 (pooled) & & & & \\
\hline \multirow[t]{2}{*}{ Flag leaf blade width } & $0.801(\mathrm{E} 1)$ & & & & \\
\hline & 0.650 (pooled) & & & & \\
\hline \multirow[t]{2}{*}{ Peduncle length } & & $0.656(\mathrm{E} 2)$ & - & - & - \\
\hline & & 0.662 (E3) & & & \\
\hline \multirow[t]{3}{*}{ Ear head length } & & - & $0.817(\mathrm{E} 2)$ & - & - \\
\hline & & & 0.716(E3), & & \\
\hline & & & 0.502 (pooled) & & \\
\hline \multirow[t]{2}{*}{ Grain yield } & & - & 0.774 (E2); & 0.720 (E3) & 0.507 (E1) \\
\hline & & & $0.583(\mathrm{E} 3)$ & & $0.575(E 3)$ \\
\hline
\end{tabular}

\section{Correlation}

The correlation coefficient helps to understand the degree of association among the different traits using phenotypic values obtained in different environments. Phenotypic correlation coefficients were calculated for the global composite collection to understand the nature of associations between different quantitative traits in all the three environments separately and overall in the three environments. In total, 367 correlations were estimated in the E1, E2, E3 and combined analysis. At probability 0.05 or less, 14 out of 66 correlations were significant in E1, 68 out of 105 in E2, 68 out of 105 in E3, and 31 out of 91 in the combined analysis of data (data not given).

The proportion of variance in one trait can be attributed to its linear relationship with a second trait and is indicated by the square of the correlation coefficient (coefficient of determination) (Snedecor and Cochran, 1980). In the present study, we have considered only those correlations, which are greater than 0.500 and smaller than -0.500 as meaningful as at least $25 \%$ of the variation of one trait is predicted by another.The pairs of correlations wereobserved such as plant height with days to $50 \%$ flowering (0.981 in E1, 0.542 in E3), with basal tiller number ( 0.770 in E1), with flag leaf blade length (0.844 in pooled), with flag leaf blade width $(0.801$ in E1, 0.650 in pooled), peduncle length with panicle excertion (0.656 in E2, 0.662 in E3), ear head length with length of longest finger (0.817 in E2, 0.716 in E3, 0.502 in pooled), grain yield with length longest finger ( 0.774 in E2, 0.583 in E3), with width of longest finger (0.720 in E3), with finger number (0.507 in E1, 0.575 in E3) (Table 1). This information would help in selecting the useful traits and thus optimize the data recording by taking observations on a few related traits in the preliminary trials involving a larger number of germplasm accessions.

\section{Diversity}

The Shannon- Weaver diversity index $\left(\mathrm{H}^{\prime}\right)$ was calculated to compare phenotypic diversity for all characters in the entire set, accessions among the races in each environment separately and also 
overall environments. Out of five morphological traits studied, The traits such as, number of the basal tiller (0.648), flag leaf sheath length (0.623), ear head width (0.607), number of fingers (0.611) in E1, days to $50 \%$ flowering $(0.619)$, culm branching $(0.615)$, panicle length (0.627), panicle excertion (0.626), length of longest finger (0.603) in E2, plant height
(0.623), flag leaf blade length (0.624), ear head length (0.603), width of longest finger (0.616) and grain yield $(0.634)$ in E3 showed high $\mathrm{H}^{`}$ compared to other two environments. The combined analysis revealed low $\mathrm{H}^{`}$ for flag leaf blade width (0.412) and high $\mathrm{H}^{`}$ for panicle excertion (0.618) (Table 2).

Table 2. Shannon-Weaver diversity index for quantitative traits of global finger millet composite collection evaluated in three environments and pooled.

\begin{tabular}{|c|c|c|c|c|}
\hline Traits & $\begin{array}{r}\text { 2005-2006 } \\
\text { Coimbatore (E1) }\end{array}$ & $\begin{array}{r}2006 \text { Rainy } \\
\text { Patancheru (E2) }\end{array}$ & $\begin{array}{r}2007 \text { Rainy } \\
\text { Patancheru (E3) }\end{array}$ & Pooled \\
\hline Days to 50 per cent flowering (days) & 0.609 & 0.619 & 0.571 & 0.599 \\
\hline Plant height (cm) & 0.616 & 0.599 & 0.623 & 0.612 \\
\hline Basal tiller numbers (number) & 0.648 & 0.587 & 0.581 & 0.605 \\
\hline Culm branching (number) & 0.531 & 0.615 & 0.531 & 0.573 \\
\hline Flag leaf blade length (mm) & 0.607 & 0.623 & 0.624 & 0.618 \\
\hline Flag leaf blade width (mm) & 0.447 & 0.343 & 0.446 & 0.412 \\
\hline Flag leaf sheath length (mm) & 0.623 & 0.576 & 0.559 & 0.586 \\
\hline Peduncle length (mm) & 0.557 & 0.627 & 0.623 & 0.602 \\
\hline Panicle exertion (mm) & 0.531 & 0.626 & 0.611 & 0.618 \\
\hline Ear head length(mm) & 0.602 & 0.596 & 0.603 & 0.6 \\
\hline Ear head width (mm) & 0.607 & 0.569 & 0.569 & 0.581 \\
\hline Length of longest finger (mm) & 0.531 & 0.603 & 0.592 & 0.597 \\
\hline Width of longest finger (mm) & 0.531 & 0.487 & 0.616 & 0.551 \\
\hline Finger number per inflorescence (number) & 0.611 & 0.408 & 0.607 & 0.542 \\
\hline Grain yield $\left(\mathrm{t} \mathrm{ha}^{-1}\right)$ & 0.617 & 0.596 & 0.634 & 0.615 \\
\hline
\end{tabular}

The mean and range of $\mathrm{H}$ for all the traits in the present study is comparable with the $\mathrm{H}^{`}$ of the entire and core collection of finger millet (Upadhyaya et al., 2006a), indicating that the composite collection represents the entire diversity.

\section{Principal component analysis}

The principal component analysis is used to provide a reduced dimension model that would indicate measured differences among groups. In all the three environments and also in the pooled analysis, a large proportion of the total variation was explained by the first seven PCs were 59.63 (E1), 62.50 (E2), 68.29 (E3) and $88.90 \%$ (pooled) variation was accounted. In the present study, from the first seven PCs, over three environments and combined analysis, the traits such as days to $50 \%$ flowering, plant height, peduncle length, ear head length and panicle exertion contributed repeatedly to total divergence at least in two environments (data not given). It revealed that these traits were contributing more towards divergence.

\section{Clustering}

Clustering was performed using a score of the first four PCs (68.29\% variation) on the pooled data based on biological race and geographical origin. Four cultivated races (elongata, plana, vulgaris and compacta) were delineated into Cluster I, whereas accessions of wild races were grouped separately in two clusters viz., Cluster II (wild spontanea) and Cluster III (wild africana) (Figure 1). The linkage distance between the wild races spontanea and africana was more than $50 \%$, so it was grouped into two different clusters. The variation of these wild races was reported at mitochondrial DNA level (Muza et al., 1995). Cytogenetically, E. coracana and $E$. africana are reported to be an allotetraploid with genomic notation of AABB with distinct genetic background (Chennaveeraiah and Hiremath, 1974). This could be the reason for difference in clustering pattern of these major sub species. This clustering observed in this study is in agreement with earlier reports based on molecular markers (RFLP, Salimath et al., 1995; RAPD, Fakrudin et al., 2004; SSR, Dida et al., 2008)

\section{Identification of diverse and traits specific diverse accessions}

By evaluating the global finger millet composite collection over three seasons, we could identify few accessions performed repeatedly better than the best control cultivar for the particular trait(s) in all environments. The number of accessions identified specific for traits were 34 for early flowering $(<50$ days), 38 for high grain yield ( $>2$ tha $^{-1}$ ), 29 for more fingers (>10), 28 for ear head length $(>150 \mathrm{~mm})$. Phenotypic diversity was calculated between each 
Table 3. Promising diverse accessions in the finger millet composite collection based on phenotypic and genotypic diversity.

\begin{tabular}{|c|c|c|c|c|}
\hline \multirow[t]{3}{*}{ Diversity nature } & \multicolumn{4}{|c|}{ Pairs of accessions showing the diversity } \\
\hline & \multicolumn{2}{|c|}{ Phenotypic diversity based on morpho-agronomic traits } & \multicolumn{2}{|c|}{ Genotypic diversity based on SSR markers data } \\
\hline & VR708 & IE3455 & IE143 & IE1011 \\
\hline \multirow{5}{*}{$\begin{array}{l}\text { Minimum diversity in } \\
\text { composite collection }\end{array}$} & VR708 & IE4789 & IE2921 & IE3826 \\
\hline & VR708 & IE61 & IE143 & IE6241 \\
\hline & VR708 & IE3802 & IE2365 & IE4956 \\
\hline & VR708 & IE3654 & IE2332 & IE2921 \\
\hline & IE5442 & IE4221 & IE2332 & IE2765 \\
\hline \multirow{4}{*}{$\begin{array}{l}\text { Maximum diversity in } \\
\text { composite collection }\end{array}$} & IE6541 & IE2084 & IE4108 & IE3238 \\
\hline & IE2441 & IE2364 & IE2288 & IE431 \\
\hline & IE4570 & IE3291 & IE2748 & IE431 \\
\hline & IE4890 & IE3130 & IE4972 & IE431 \\
\hline \multicolumn{5}{|c|}{ Trait specific accessions showing maximum diversity } \\
\hline \multirow{5}{*}{ Early Flowering } & IE4755 & IE2275 & IE49 & IE2275 \\
\hline & IE4759 & IE3543 & IE4442 & IE2323 \\
\hline & IE2393 & IE3537 & IE3537 & IE2329 \\
\hline & IE4442 & IE2957 & IE583 & IE4759 \\
\hline & IE4734 & IE2293 & IE2275 & IE2083 \\
\hline \multirow{5}{*}{ High finger number } & IE4866 & IE4257 & IE2578 & IE3802 \\
\hline & IE4677 & IE4563 & IE96 & IE2340 \\
\hline & IE5689 & IE4476 & IE3194 & IE6236 \\
\hline & IE2957 & IE6013 & IE2773 & IE96 \\
\hline & IE5877 & IE4476 & IE5198 & IE2587 \\
\hline \multirow{5}{*}{ More finger length } & IE6548 & IE2108 & IE6252 & IE4677 \\
\hline & IE3046 & IE3722 & IE5689 & IE5877 \\
\hline & IE3489 & IE2789 & IE3790 & IE4586 \\
\hline & IE5321 & IE3046 & IE6059 & IE4476 \\
\hline & IE2608 & IE2223 & IE2591 & IE5956 \\
\hline \multirow{5}{*}{ High grain yield/ha } & IE2773 & IE5472 & IE2678 & IE3802 \\
\hline & IE2684 & IE2299 & IE6236 & IE3194 \\
\hline & IE4600 & IE2590 & IE2340 & IE2992 \\
\hline & IE4121 & IE2827 & IE5198 & IE3194 \\
\hline & IE3663 & IE4600 & IE5198 & IE2712 \\
\hline
\end{tabular}

pair of accessions for 15 quantitative traits. The diversity index was calculated by averaging all the difference in the phenotypic value for each trait divided by their respective range (Johns et al., 1997).

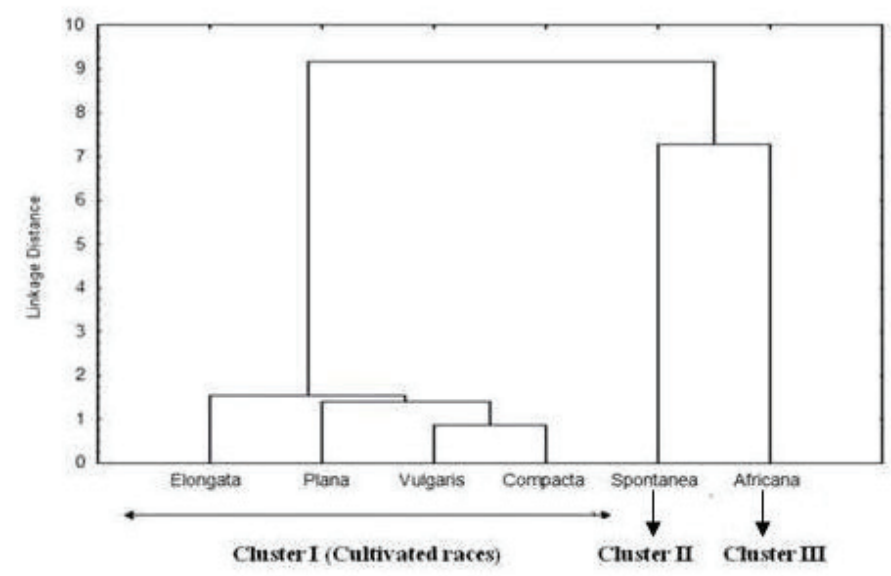

Figure 1. Ward's clustering of finger millet global composite collection concerning races based on scores of first four PCs 
In the entire composite collection, the mean phenotypic diversity was 0.8423 . The maximum phenotypic diversity (0.990) was observed between the accessions IE5442 and IE4221 and least diversity (0.156) was observed between the pair of accessions such as VR708 with IE3455. In the trait specific accessions, most phenotypic diversity was observed between the accessions IE4755 and IE2275 (early flowering); IE4866 and IE4257 (more finger number); IE6548 and IE2108 (high finger length); IE2773 and IE5472 (grain yield) (Table 3).

Based on the dissimilarity matrix of 20 SSR markers data on 959 accessions (41 accessions excluded from the analysis due to poor quality), the most genotypic diversity in the composite collection was identified between IE2332 and IE2765 and least diversity between IE5442 and IE4224. Among the trait-specific accessions, most genotypic diversity was observed between the accessions IE49 and IE2275 (early flowering); IE2578 and IE3802 (more finger number); IE6252 and IE4677 (high finger length); IE2678 and IE3802 (high grain yield) (Table 3). There was no correspondence between the highly diverse pair of identified accessions using phenotypic and genotypic diversity in any of the traits. This could be due to that the diversity detected by these limited number of SSR markers does not reflect the diversity associated with these important traits.

\section{CONCLUSION}

By evaluating the global finger millet composite collection in a different environment, the traitspecific accessions were identified, which would serve as new sources of variation in finger millet crop improvement. The most diverse pairs of accessions were identified in the composite collection based on the diversity index for phenotypic diversity and SSR based dissimilarity matrix for genotypic diversity. It would be interesting and to involve the most diverse lines in the hybridization program to see the extent of segregation for different traits. The inclusion of these diverse germplasm lines from such collections in the hybridization programs would increase the dominance effect and epistatic variation in the inheritance of quantitative traits.

\section{REFERENCES}

Chennaveeraiah., M.S and S.C. Hiremath. 1974. Genome analysis of Eleusine coracana (L.) Gaertn. Euphytica. 23: 489-495.
Dida., M.M, N. Wanyera, M.L.N. Harrison Dunn, J.L. Bennetzen, and K.M. Devos. 2008. Population structure and diversity in finger millet (Eleusine coracana) germplasm. Tropical Plant Biology, DOI $10.1007 /$ s1 2042-008-9012-3.

Fakrudin, B, H.E Shashidhar, R.S Kulkarni, and S Hittalmani. 2004. Genetic diversity assessment of finger millet, (Eleusine coracana (L) Gaertn.), germplasm through RAPD analysis. PGR Newsletter. 138: $50-54$.

Halward, T,M and J,C Wynne. 1991. Generation mean analysis for productivity in two diverse peanut crosses. Theoretical and Applied Genetics 82, 784-792.

Hilu., K.W, J.M.J de Wet, and J.R Harlan. 1979. Archeobotany and the origin of finger millet. Amer. J. Bot, 66: 330-333.

Johns, M.A, P.W Skroch, J. Nienhuis, P. Hinrichsen, G. Bascur and C. Munoze-schick. 1997. Gene pool classification of common bean landraces from Chile based on RAPD and morphological data. Crop Science. 37:605-613.

Muza, F,R, D,J Lee, D,J Andrews and S,C Gupta. 1995. Mitochondrial DNA variation in finger millet (Eleusine coracana). Euphytica. 81:199-205.

Payne., R.W, D.A Murray, S.A. Harding, D.B. Baird and D.M. Soutar. 2007. GenStat for Windows (10th Edition) Introduction. VSN International, Hemel Hempstead [Online]. Available at http://www.vsni. co.uk (verified 9 June 2010).

Salimath., S.S, A.C. de Oliveira, I.D. Godwin and J.L Bennetzen. 1995. Assessment of genome origins and genetic diversity in the genus Eleusine with DNA markers. Genome.38: 757-763.

Shannon, C.E, and W. Weaver. 1949. The mathematical theory of communication. The bell system technical journal;27, PP. 379 - .656

Snedecor, G.W and W.G Cochran. 1980. Statistical methods. $7^{\text {th }}$ ed. Iowa State Univ. Press, Ames. Skinner, D.Z., G.R. Bauchan, G. Auricht, and S. Hughes. 1999. A method for efficient management and utilization of large germplasm collections. Crop Sci. 39:1237-1242.

Upadhyaya, H.D, C.L.L. Gowda, R.P.S Pundir, V.G. Reddy and S. Singh. 2006a. Development of core subset of finger millet germplasm using geographical origin and data on 14 quantitative traits. Genetic Resources and Crop Evolution,53: 679-685.

Upadhyaya., H.D, R.K. Varshney, D.A Hoisington, C.L.L. Gowda, C.T. Hash, VG Reddy, S Chandra, A. Bharathi, and N .Lalitha. 2006b. Genotyping of Finger millet. Poster presented at Generation Challenge Programme. ARM meeting. Brazil.

Ward., J. 1963. Hierarchical grouping to optimize an objective function. Journal of American Stat. Assoc 38:236-244 